\title{
Communication
}

\section{Soluble Expression of Small Antibody Fragments against PD-L1 Using Escherichia coli with High Yield and Purity}

\author{
Sun-Hee Kim ${ }^{1}$ and Hee-Jin Jeong ${ }^{2, *}$ \\ 1 Industry-Academia Cooperation Foundation, Hongik University, 2639 Sejong-ro, Jochiwon-eup, \\ Sejong-si 30016, Korea; marian8151@hongik.ac.kr \\ 2 Department of Biological and Chemical Engineering, Hongik University, 2639 Sejong-ro, Jochiwon-eup, \\ Sejong-si 30016, Korea \\ * Correspondence: heejinjeong@hongik.ac.kr
}

Citation: Kim, S.-H.; Jeong, H.-J. Soluble Expression of Small Antibody Fragments against PD-L1 Using Escherichia coli with High Yield and Purity. Appl. Sci. 2021, 11, 9149. https://doi.org/10.3390/app11199149

Academic Editor: John Patrick Alao

Received: 31 August 2021

Accepted: 29 September 2021

Published: 1 October 2021

Publisher's Note: MDPI stays neutral with regard to jurisdictional claims in published maps and institutional affiliations.

Copyright: (c) 2021 by the authors. Licensee MDPI, Basel, Switzerland. This article is an open access article distributed under the terms and conditions of the Creative Commons Attribution (CC BY) license (https:/ / creativecommons.org/licenses/by/ $4.0 /)$.

\begin{abstract}
Programmed death-ligand 1 (PD-L1) is a surface protein overexpressed in tumor cells Recently, targeted therapy using PD-L1 antibodies to reconstitute the antitumor activity of T cells has received considerable attention as a cancer treatment. Among the several types of anti-PD-L1 antibodies, small-sized antibody fragments are useful agents to block PD-L1 for experimental and therapeutic purposes owing to their high penetration efficacy toward dense tumor cells. Herein, we expressed and purified recombinant single chain fragment of variable domain, variable heavy chain, and variable light chain, against PD-L1 in a soluble form using Escherichia coli, resulting in their high yield and high purity. We confirmed the antigen-binding efficiency of these antibody fragments, which showed antigen concentration-dependent responses. These results suggest that these small antibody fragments can serve as new agents for blocking or detecting PD-L1.
\end{abstract}

Keywords: programmed death-ligand 1; recombinant antibody; single chain Fvs; single domain antibody; soluble expression; Escherichia coli

\section{Introduction}

Programmed death-ligand 1 (PD-L1), which is overexpressed on the surface of tumor cells, is a transmembrane protein that interacts with programmed cell death-1 (PD-1), which is expressed on the surface of T cells [1]. PD-L1 binds to PD-1, blocks T cell activities, such as migration, proliferation, blocks the secretion of cytotoxic mediators, and consequently limits tumor cell death [1,2]. As antibodies bind to PD-L1 and block the binding of PD-L1 to PD-1, monoclonal anti-PD-L1 antibodies have been generated to prevent the inhibition of the activation of tumor cells. However, monoclonal antibody production is costly and requires unstable hybridoma cell culture or generation of antibody libraries via phage display technology. Moreover, the size of full-length antibodies can disrupt antibody penetration into dense tumor cells. To overcome these issues, the need for generating recombinant antibody fragments has increased.

A single chain variable fragment ( $\mathrm{scFv}$ ) is an antibody fragment consisting of a variable heavy chain $(\mathrm{VH})$ and a variable light chain $(\mathrm{VL})$ of one arm of an antibody linked together via a flexible polypeptide linker (Figure 1). ScFvs retains specificity and affinity for their antigens without a constant region of antibody [3]. Moreover, owing to their small size, scFvs have demonstrated higher tissue-penetrating capabilities than full-sized antibodies [4-6]. Furthermore, the reduced complexity of scFvs allows for rapid and large-scale production in Escherichia coli (E. coli), which is beneficial owing to the reduced labor intensity and more rapid growth rate compared with eukaryotic hosts [7,8]. In addition to scFvs, single domain antibodies (sdAbs), which are unpaired variable domain of antibody ( $\mathrm{VH}$ and VL), have also been applied as a promising biologic modality. SdAbs are expected to be imaging and therapeutic reagents in vivo because their smaller molecular size compared 
with other fragments, such as antigen-binding fragment (Fab) and scFv, enables high tissue penetration and rapid elimination from the body.
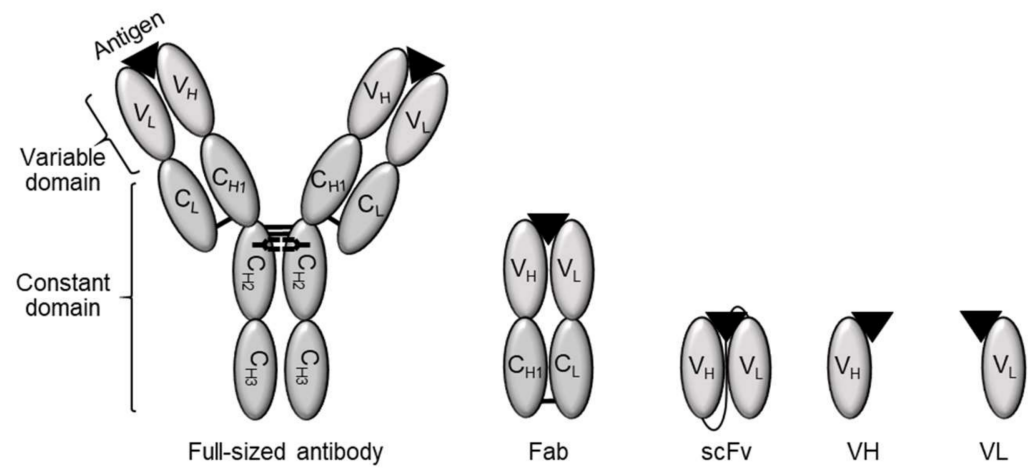

Figure 1. Schematic representations of full-sized antibody, antigen-binding fragment (Fab), single chain variable fragment (scFv), variable heavy chain $(\mathrm{VH})$, and variable light chain (VL).

In this study, we constructed three recombinant DNAs encoding antibody fragments- $\mathrm{scFv}$, $\mathrm{VH}$, and VL-against mouse PD-L1 and expressed them in E. coli in a soluble form. After purification, we compared PD-L1-binding efficiencies of the three antibody fragments to highlight their capabilities as attractive reagents for blocking or detecting PD-L1.

\section{Materials and Methods}

\subsection{Materials}

Restriction enzymes and E. coli SHuffle T7 Express lysY were obtained from New England Biolabs (Seoul, Korea). Oligonucleotides and the plasmid Miniprep kits were obtained from Bionics (Seoul, Korea). Herculase II Fusion DNA polymerase was from Agilent Genomics (Seoul, Korea). Ligation high ver2 was obtained from Toyobo (Osaka, Japan). KOD-plus Neo DNA polymerase, KOD-One DNA polymerase, In-Fusion HD cloning kit, Talon metal affinity resin were from Takara-Bio (Otsu, Japan). Gravity empty column was from Bio-Rad (Daejeon, Korea). Ultrafiltration devices were obtained from Pall (Nanosep Centrifugal-3 k; MI, USA). Recombinant mouse PD-L1 protein was obtained from Sino Biological Inc. (Beijing, China). HRP-conjugated anti-Flag antibody was obtained from BioLegend (California, CA, USA). Other chemicals and reagents, unless otherwise indicated, were from Sigma (Seoul, Korea).

\subsection{Gene Construction}

The anti-mouse PD-L1 scFv coding gene (GenBank: KF041825.1) with both an Nterminal Cys-tag and a C-terminal His- and Flag- tags was chemically synthesized and amplified by polymerase chain reaction (PCR) using primers pSQinsertFw55 and pSQinsertRv57, and KOD-plus Neo DNA polymerase. The product was digested using AgeI and HindIII, then inserted into AgeI- and HindIII-digested pSQ::aBGPscFv [9] using ligation high ver2, resulting in PSQ::aPDL1scFv. Afterwards, an N-terminal Srt-tag was added in front of the Cys-tag by PCR using primers CysToSrtCys_Fw and Infusion_HisToHisFlag-Rv, Herculase II Fusion DNA Polymerase, and pSQ::aPDL1scFv as a template. The product was inserted into AgeI- and BamHI-digested pSQ::aPDL1scFv, resulting in pSrtCys::PDL1.

To construct pSrtCys::aPDL1VH, VH domain of pSrtCys::aPDL1scFv was digested using NdeI and BgIII, and the extracted DNA was amplified by PCR using primers pSQinsertFw55 and aPDL1VH_Rv_infusion, and Herculase II Fusion DNA Polymerase. Vector DNA was amplified by PCR using primers vectorPCR_NdeI_Rv and vectorPCR_BamHI_Fw, and KOD-plus Neo DNA polymerase. The purified PCR products were ligated using an In-Fusion HD cloning kit, resulting in pSrtCys::aPDL1VH.

To construct pSrtCys::aPDL1VL, VH domain was eliminated from pSrtCys::aPDL1scFv using primers VH_deletion_Fw and VH_deletion_Rv, pSrtCys::aPDL1scFv as a template, and KOD-One DNA polymerase. The PCR product was incubated at $37^{\circ} \mathrm{C}$ for $2 \mathrm{~h}$ with 
$10 \mathrm{U}$ DpnI, followed by inactivation of the enzyme at $80{ }^{\circ} \mathrm{C}$ for $20 \mathrm{~min}$, resulting in pSrtCys::aPDL1VL.

The primer sequences are listed in Table 1 . The obtained plasmids were prepared using the plasmid Miniprep system, and the entire coding-region sequences were confirmed by sequencing (Table 2).

Table 1. Nucleotide sequences of primers used in this study.

\begin{tabular}{|c|c|}
\hline Primer Name & Sequence $\left(5^{\prime}-3^{\prime}\right)$ \\
\hline pSQinsertFw55 & ggagatatacatatggctcaaatcg \\
\hline pSQinsertRv57 & gtcatcgtcgtccttgtagtc \\
\hline CysToSrtCys_Fw & tatacatatgggcggtggaggtggtgctcaaatcgaag \\
\hline Infusion_HisToHisFlag-Rv & tgtagtcggatccgccatgatgatgatgatgat \\
\hline aPDL1VH_Rv_infusion & tgtagtcggatccgccatgatgatgatgatgatgagaacссссссссаgatctagaggactgac \\
\hline vectorPCR_NdeI_Rv & gagccatatgtatatctcc \\
\hline vectorPCR_BamHI_Fw & atggcggatccgactac \\
\hline VH Deletion Fw & aggcggccetgacgttggacgagtcc \\
\hline VH Deletion Rv & agggccgcctgggccacggtagc \\
\hline
\end{tabular}

Table 2. Nucleotide sequences of anti-PDL1 scFv, anti-PDL1 VH, and anti-PDL1 VL with tags. Bold: linker, underline: His-tag, underlined italic: Flag-tag.

\begin{tabular}{|c|c|}
\hline & Sequence $\left(5^{\prime}-3^{\prime}\right)$ \\
\hline $\mathrm{scFv}$ & 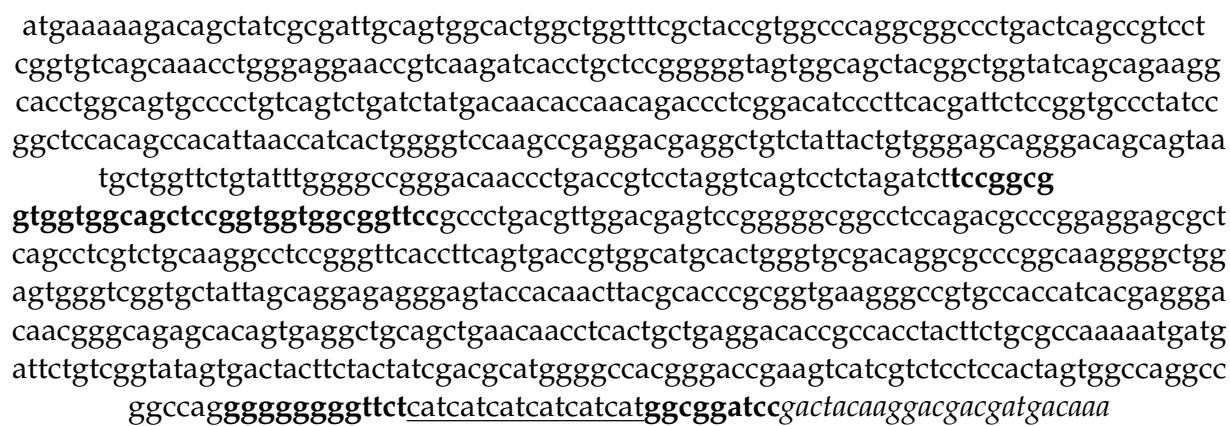 \\
\hline $\mathrm{VH}$ & 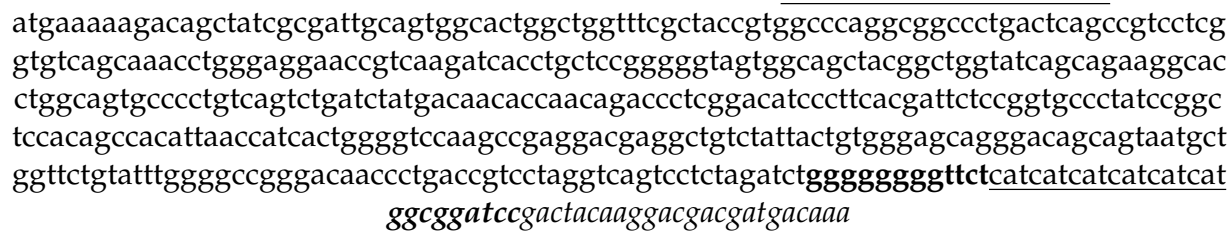 \\
\hline VL & 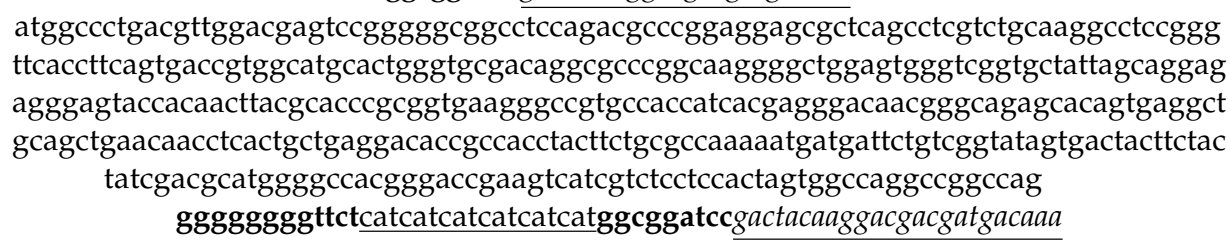 \\
\hline
\end{tabular}

\subsection{Expression and Purification of Antibody Fragments}

SHuffle T7 Express lysY cells were transformed with each expression vector (pSrtCys::aPDL1scFv, pSrtCys::aPDL1VH, and pSrtCys::aPDL1VL) and cultured at $37^{\circ} \mathrm{C}$ for $16 \mathrm{~h}$ in LBA medium (LB medium containing $100 \mu \mathrm{g} / \mathrm{mL}$ ampicillin) and $1.5 \%$ agar. A single colony was picked and grown at $30^{\circ} \mathrm{C}$ in $4 \mathrm{~mL}$ of LBA medium for overnight, from which $1 \mathrm{~mL}$ was used to inoculate $100 \mathrm{~mL}$ of LBA medium or 2xYTA medium (2xYT medium containing $100 \mu \mathrm{g} / \mathrm{mL}$ ampicillin). The cells were cultured at $37^{\circ} \mathrm{C}$ to an OD600 of 0.8 , after which $1 \mathrm{mM}$ isopropylthio- $\beta$-galactopyranoside (IPTG) was added. The solution was incubated for an additional $16 \mathrm{~h}$ at $37^{\circ} \mathrm{C}$ for inducing aPDL1scFv or $20 \mathrm{~h}$ at $16^{\circ} \mathrm{C}$ for inducing aPDL1VH and aPDL1VL, followed by centrifugation $(4000 \times g$ for $20 \mathrm{~min}$ at $\left.4{ }^{\circ} \mathrm{C}\right)$. The pellet was washed using $10 \mathrm{~mL}$ of binding buffer $(50 \mathrm{mM}$ phosphate buffered 
saline (PBS, pH 7.4), 0.5 M sodium chloride ( $\mathrm{NaCl}), 10 \mathrm{mM}$ imidazole, and $5 \%$ glycerol (pH 7.4)), and resuspended in $15 \mathrm{~mL}$ of lysis buffer (50 mM PBS (pH 7.4), $0.5 \mathrm{M} \mathrm{NaCl}$, $10 \mathrm{mM}$ imidazole, $5 \%$ glycerol, and $1 \mathrm{mM}$ PMSF), followed by sonication ( $50 \%$ power, $2 \mathrm{sec}$ on/off). After centrifugation (13,000 rpm for $30 \mathrm{~min}$ at $\left.4{ }^{\circ} \mathrm{C}\right)$, the supernatant was purified via gravity purification method using $2 \mathrm{~mL}$ of TALON metal-affinity resin-packed column as follows: the supernatant was bound to bead at $4{ }^{\circ} \mathrm{C}$, and the beads were washed with $15 \mathrm{~mL}$ of binding buffer followed by $60 \mathrm{~mL}$ of washing buffer ( $50 \mathrm{mM}$ PBS, $0.5 \mathrm{M}$ $\mathrm{NaCl}$, and $20 \mathrm{mM}$ imidazole). After series addition of $1 \mathrm{~mL}$ of elution buffer (50 mM PBS, $0.3 \mathrm{M} \mathrm{NaCl}$, and $250 \mathrm{mM}$ imidazole), each fraction was collected using a disposable gravity column. The eluent was subjected to an ultrafiltration device ( $3 \mathrm{k})$, equilibrated with PBS, and concentrated to $250 \mu \mathrm{L}$. Protein expression and purification were confirmed by sodium dodecyl sulfate polyacrylamide gel electrophoresis (SDS-PAGE) analysis, and protein concentration was determined on the gel using various concentrations of bovine serum albumin (BSA) as a standard.

\subsection{Enzyme-Linked Immunosorbent Assay}

The antigen-binding activities of three recombinant antibody fragments were confirmed by indirect enzyme-linked immunosorbent assay (ELISA). The 96-well microplate (Maxi-binding, SPL) was coated with $50 \mu \mathrm{L} /$ well of several concentrations of mPDL1 in PBS at $4{ }^{\circ} \mathrm{C}$ for overnight. The plate was blocked at $25{ }^{\circ} \mathrm{C}$ for $2 \mathrm{~h}$, with $3 \%$ skim milk in PBST (PBS with $0.05 \%$ Tween20), washed three times with PBS, and incubated with $100 \mu \mathrm{g} / \mathrm{mL}$ of antibody fragments in PBST at $25^{\circ} \mathrm{C}$ for $1 \mathrm{~h}$. The plate was washed and incubated with $50 \mu \mathrm{L} /$ well of 20,000-fold diluted HRP-conjugated anti-Flag antibody in PBST at $25^{\circ} \mathrm{C}$ for $1 \mathrm{~h}$. The plate was then washed three times with PBS and developed with $50 \mu \mathrm{L} /$ well TMBZ solution. After incubation for $5 \mathrm{~min}$, the reaction was stopped by adding $50 \mu \mathrm{L} /$ well of $10 \%$ sulfuric acid, and the absorbance was read using a microplate reader at $450 \mathrm{~nm}$.

\section{Results}

\subsection{Antibody Fragment-Expressing Plasmids}

The DNA sequence of anti-mPD-L1 scFv used in this study (GenBank: KF041825.1) was originally generated by phage display followed by screening via biopanning [10]. We genetically synthesized the anti-mPD-L1 scFv gene and performed subcloning to insert scFv-, VH-, or VL-expressing genes into the pSrtCys vector, which is a pET32b-based protein-expressing vector modified with Srt-tag and Cys-tag for conjugating a dye at the $\mathrm{N}$-terminal region of each antibody fragment (in preparation). We added a His-tag at the C-terminal region of each antibody fragment to purify the antibody fragments after cytoplasmic expression, followed by a Flag-tag for enabling detection via ELISA (Figure 2A, Table 2).

\subsection{Expression and Purification of Antibody Fragments}

We expressed three antibody fragments- $\mathrm{scFv}, \mathrm{VH}$, and $\mathrm{VL}-$ in E. coli in a soluble form and purified cytosolic proteins using immobilized metal affinity chromatography. To improve expression yield and purity, we optimized the culture medium, induction temperature, induction time, IPTG concentration, imidazole concentration in the washing buffer, and the volume of the washing buffer. Finally, we confirmed that highly purified $\mathrm{scFv}$ fragments with expected sizes of $31.25 \mathrm{kDa}$ were obtained in a soluble form, in 2xYTA medium with $1 \mathrm{mM}$ IPTG induction for $16 \mathrm{~h}$ at $37^{\circ} \mathrm{C}$, and $20 \mathrm{mM}$ imidazole containing washing buffer (Figure 2B). Notably, $564.2 \mu \mathrm{g}$ of purified scFv was obtained from the $100 \mathrm{~mL}$ shake-flask culture, which exceeded the yield of anti-mPD-L1 scFv, obtained from periplasmic protein extraction by Jeremy et al. (1 $\mathrm{mg}$ from a $250 \mathrm{~mL}$ culture) [10], signifying the importance of optimizing expression, induction conditions, and cloning vectors to improve expression yield, even for cases with similar insert DNA sequences. Subsequently, we produced anti-PD-L1 VH and anti-PD-L1 VL under the same expression and purification 
conditions to anti-PD-L1 scFv. However, VH and VL expression levels were not as high as those of $\mathrm{scFv}$, so expression conditions were further optimized. Consequently, we successfully obtained $516 \mu \mathrm{g}$ and $109 \mu \mathrm{g}$ of VH and VL from the $100 \mathrm{~mL}$ culture, respectively, after induction for $20 \mathrm{~h}$ at $16^{\circ} \mathrm{C}$. We further performed a ultrafiltration and confirmed that the $\mathrm{scFv}, \mathrm{VH}$, and $\mathrm{VL}$ were expressed with high purity (Figure 2C).

(A)
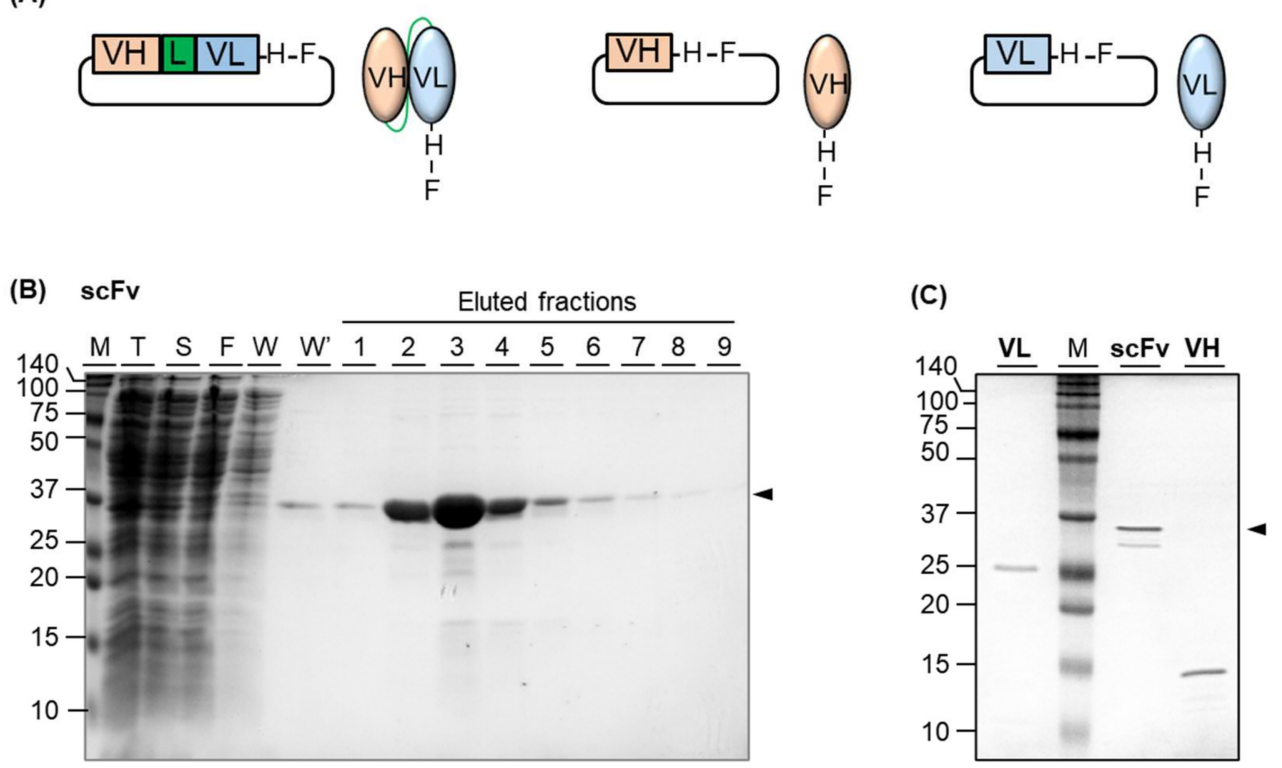

Figure 2. (A) Schematic representation of DNA plasmids and antibody fragments. L, H, and F indicates GS linker, His-tag, and Flag-tag, respectively. (B) Fractions at the purification step of anti-PD-L1 scFv. M, T, S, F, W, W', and numbers indicates marker, total reagent after sonication, supernatant after centrifugation of sonicated protein, flow through fraction, washing fraction using a buffer including no imidazole, washing fraction using a buffer including $20 \mathrm{mM}$ imidazole, and the order of eluted fractions using a buffer including $250 \mathrm{mM}$ imidazole, respectively. (C) SDS-PAGE analysis of purified $\mathrm{scFv}, \mathrm{VH}$, and $\mathrm{VL}$ after buffer changing using an ultrafiltration.

\subsection{Confirmation of Antigen-Binding Efficiency}

We examined antigen-binding activity for each antibody fragment by performing indirect ELISA. We seeded commercially available mPD-L1 protein into a 96-well plate and blocked the wells using skim milk. Subsequently, we added each antibody fragment as the primary antibody followed by HRP-conjugated anti-Flag antibody as the secondary antibody (Figure 3A). As a result, we obtained the signals of all three antibody fragments, which increased in an antigen concentration-dependent manner. In contrast, without antigens, negligible signals were observed, indicating that each antibody fragment retained the antigen-binding activity. When $100 \mathrm{ng} \mathrm{scFv}, 1000 \mathrm{ng} \mathrm{VH}$, and $1000 \mathrm{ng} \mathrm{VL}$ were used, the EC50 values of scFv, $\mathrm{VH}$, and $\mathrm{VL}$ were $0.325 \pm 0.021 \mathrm{ng} / \mu \mathrm{L}, 1.127 \pm 0.144 \mathrm{ng} / \mu \mathrm{L}$, and $0.429 \pm 0.144 \mathrm{ng} / \mu \mathrm{L}$, respectively (Figure $3 \mathrm{~B}-\mathrm{D}$ ). The limit of detection (LOD) values for $\mathrm{scFv}, \mathrm{VH}$, and $\mathrm{VL}$, were $0.026 \mathrm{ng} / \mu \mathrm{L}, 0.523 \mathrm{ng} / \mu \mathrm{L}$, and $0.077 \mathrm{ng} / \mu \mathrm{L}$, respectively. The binding efficiencies of $100 \mathrm{ng} \mathrm{VH}$ and $100 \mathrm{ng} \mathrm{VL}$ were lower than the binding efficiency of $100 \mathrm{ng} \mathrm{scFv}$. This finding was as predicted because sdAbs only have one binding site as opposed to two of scFvs. However, when we used increased amounts of VH and VL (1000 ng), those EC50 and LOD showed similar values to the $100 \mathrm{ng} \mathrm{scFv}$, indicating the usefulness of VH and VL as antibody fragments for detecting PD-L1 with high sensitivity. 
(A)

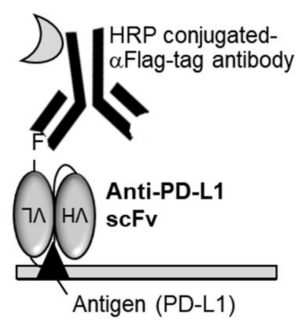

(c)

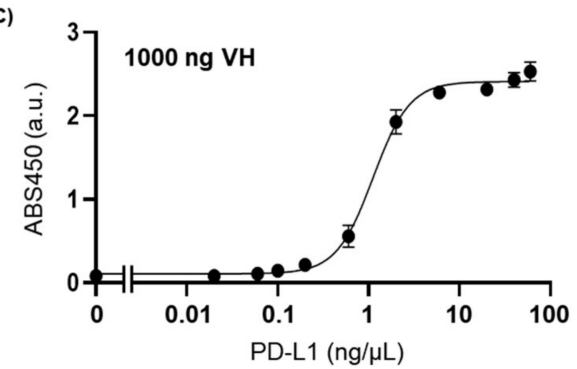

(B)

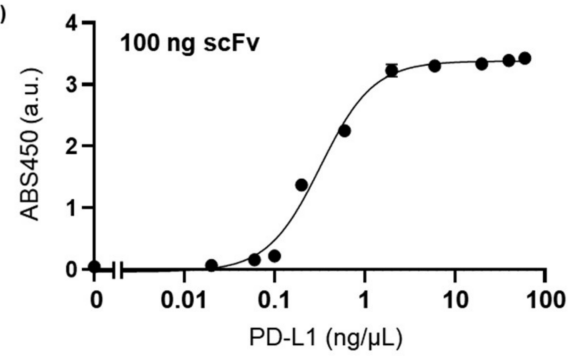

(D)

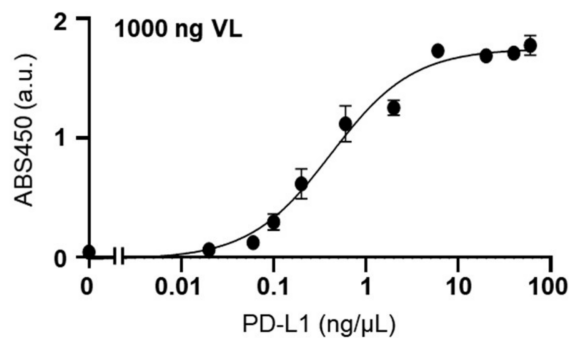

Figure 3. (A) Schematic representation of the indirect ELISA for confirming the dose-dependent PD-L1-binding efficiency of recombinant antibody fragments; (B) ELISA signal of $100 \mathrm{ng}$ anti-PD-L1 scFv with various concentrations PD-L1; (C) ELISA signal of $1000 \mathrm{ng}$ anti-PDL1 VH with various concentrations PD-L1; (D) ELISA signal of $1000 \mathrm{ng}$ anti-PD-L1 VL with various concentrations of PD-L1. Error bars represent \pm 1 SD $(\mathrm{n}=3)$.

\section{Discussion}

Full-sized antibodies have been used as therapeutic agents against immunological disorders. However, their large size leads to low tissue accessibility and penetration, thereby affecting their therapeutic efficacy [11]. Therefore, smaller engineered antibody fragments have become promising alternatives to full-sized antibodies [12]. ScFvs (approximately 30-35 kDa) and sdAbs (approximately 15-20 kDa) have inherent advantages over full-sized antibodies (approximately $150 \mathrm{kDa}$ ), including smaller sizes, relatively low production costs, and improved robustness, and have thus attracted considerable scientific attention and applications [13]. Therefore, potential antibody fragment-based cancer therapies using scFv and sdAbs against PD-L1 developed in this study would be particularly important in biomedical and pharmaceutical fields. Moreover, for antibody engineering, sdAbs could enable the production of novel multivalent constructs, such as combination antibodies and bispecific antibodies. Furthermore, sdAbs are characterized by their unique biophysical features, e.g., pharmacological features, such as lower immunogenicity than scFv and alpaca-based VHH having a size similar to VH and VL. Despite the advantages of scFvs and sdAbs, some issues need to be addressed. First, they have a shorter half-life than Fab or full-sized antibodies. This could be improved by conjugating engineered Fc-based constructs, such as monomeric IgG CH3 or CH2-CH3 hybrids [14-18]. This strategy can rescue fused scFvs or sdAbs from endosomal degradation, although such fusion will result in an increase in the size. Second, the GS linker of scFv, which links VH and VL, could potentially incur some immunogenicity because the GS peptide is a non-native antibody sequence. Hence, it would be preferable to use VH or VL instead of scFv, despite the lower sensitivity of sdAbs than scFv. Lastly, future research should focus on exploiting $\mathrm{sdAb}$ affinities. Sensitivity-related biophysical properties can be exploited by introducing mutations in complementarity-determining regions followed by screening from libraries that allow a more hydrophilic VH-VL interface and/or higher affinity $[19,20]$.

Herein, we used E. coli as host cells owing to the shorter growth time and to the less production cost than those of mammalian cells and yeasts. This allows rapid and 
cost-effective production of antibody fragments in large quantities. In addition, the transformation of E. coli with nanogram amounts of DNA by convenient heat shock treatment shows high efficiency in comparison to the transformation of mammalian cells, which requires expensive transfection reagent. E. coli lacks subcellular compartments, such as olgi apparatus and endoplasmic reticulum, which are necessary to facilitate glycosylation [21]. However, as $\mathrm{scFv}$ and $\mathrm{sdAb}$ do not require glycosylation, whereas full-sized antibody is glycosylated at its hinge and Fc region, it was not an obstacle to produce the antibody fragments in E. coli, while full-sized antibody cannot be properly be formed via the E. coli-based expression system [22-24]. However, E. coli-based expression can trigger an endotoxic immune response that leads to toxic shock in humans and/or can induce contamination of the sample due to the presence of lipopolysaccharides (LPS) [21]. To resolve this issue and further improve the application of the scFv and sdAbs developed in this study for use in clinical trials, including cancer treatment, size-exclusion chromatography or anti-LPS antibody-based affinity purification would be useful in removing LPS after large-scale production of antibody fragments.

In this study, we generated scFv and sdAbs against PD-L1 and demonstrated their antigen-binding efficiency. Plasmid DNA sequences, as well as optimized conditions for expressing these proteins in a soluble form can help produce antibody fragments with high yield and purity. We expect that these antibody fragments can be used as attractive cancer-related diagnostic and therapeutic agents for blocking PD-L1/PD-1 signaling.

Author Contributions: Conceptualization, H.-J.J.; methodology, S.-H.K.; formal analysis, S.-H.K. and H.-J.J.; investigation, S.-H.K. and H.-J.J.; data curation, S.-H.K.; writing, S.-H.K. and H.-J.J.; visualization, S.-H.K.; supervision, H.-J.J.; funding acquisition, H.-J.J. All authors have read and agreed to the published version of the manuscript.

Funding: This research was funded by an NRF grant and Korea Medical Device Development Fund grant funded by the Korean government: NRF-2020R1I1A307411712, KMDF_PR_20200901_0073; WISET grant funded by the Ministry of Science, and ICT(MSIT) Program for Returners into R\&D:202024); a 2021 Hongik University Research Fund.

Institutional Review Board Statement: Not applicable.

Informed Consent Statement: Not applicable.

Acknowledgments: We thank Jae-Geun Lee for his technical help with cloning.

Conflicts of Interest: The authors declare no conflict of interest.

\section{References}

1. Akinleye, A.; Rasool, Z. Immune checkpoint inhibitors of PD-L1 as cancer therapeutics. J. Hematol. Oncol. 2019, 12, 92. [CrossRef]

2. Butte, M.J.; Keir, M.E.; Phamduy, T.B.; Sharpe, A.H.; Freeman, G.J. Programmed death-1 ligand 1 interacts specifically with the B7-1 costimulatory molecule to inhibit T cell responses. Immunity 2007, 27, 111-122. [CrossRef] [PubMed]

3. Peterson, E.; Owens, S.M.; Henry, R.L. Monoclonal antibody form and function: Manufacturing the right antibodies for treating drug abuse. AAPS J. 2006, 8, E383-E390. [CrossRef]

4. Chames, P.; Van Regenmortel, M.; Weiss, E.; Baty, D. Therapeutic antibodies: Successes, limitations and hopes for the future. Br. J. Pharmacol. 2009, 157, 220-233. [CrossRef]

5. Beckman, R.A.; Weiner, L.M.; Davis, H.M. Antibody constructs in cancer therapy: Protein engineering strategies to improve exposure in solid tumors. Cancer 2007, 109, 170-179. [CrossRef] [PubMed]

6. Yokota, T.; Milenic, D.E.; Whitlow, M.; Schlom, J. Rapid tumor penetration of a single-chain Fv and comparison with other immunoglobulin forms. Cancer Res. 1992, 52, 3402-3408.

7. Terpe, K. Overview of bacterial expression systems for heterologous protein production: From molecular and biochemical fundamentals to commercial systems. Appl. Microbiol. Biotechnol. 2006, 72, 211-222. [CrossRef] [PubMed]

8. Makrides, S.C. Strategies for achieving high-level expression of genes in Escherichia coli. Microbiol. Rev. 1996, 60, 512-538. [CrossRef] [PubMed]

9. Jeong, H.-J.; Kawamura, T.; Dong, J.; Ueda, H. Q-Bodies from Recombinant Single-Chain Fv Fragment with Better Yield and Expanded Palette of Fluorophores. ACS Sens. 2016, 1, 88-94. [CrossRef]

10. Drees, J.J.; Augustin, L.B.; Mertensotto, M.J.; Schottel, J.L.; Leonard, A.S.; Saltzman, D.A. Soluble production of a biologically active single-chain antibody against murine PD-L1 in Escherichia coli. Protein Expr. Purif. 2014, 94, 60-66. [CrossRef] 
11. Samaranayake, H.; Wirth, T.; Schenkwein, D.; Räty, J.K.; Ylä-Herttuala, S. Challenges in monoclonal antibody-based therapies. Ann. Med. 2009, 41, 322-331. [CrossRef]

12. Holliger, P.; Hudson, P.J. Engineered antibody fragments and the rise of single domains. Nat. Biotechnol. 2005, 23, 1126-1136. [CrossRef]

13. Wu, Y.; Jiang, S.; Ying, T. Single-Domain Antibodies As Therapeutics against Human Viral Diseases. Front. Immunol. 2017, 8 , 1802. [CrossRef]

14. Ying, T.; Chen, W.; Feng, Y.; Wang, Y.; Gong, R.; Dimitrov, D.S. Engineered soluble monomeric IgG1 CH3 domain: Generation, mechanisms of function, and implications for design of biological therapeutics. J. Biol. Chem. 2013, 288, 25154-25164. [CrossRef]

15. Ying, T.; Ju, T.W.; Wang, Y.; Prabakaran, P.; Dimitrov, D.S. Interactions of IgG1 CH2 and CH3 Domains with FcRn. Front. Immunol. 2014, 5, 146. [CrossRef]

16. Ying, T.; Wang, Y.; Feng, Y.; Prabakaran, P.; Gong, R.; Wang, L.; Crowder, K.; Dimitrov, D.S. Engineered antibody domains with significantly increased transcytosis and half-life in macaques mediated by FcRn. MAbs 2015, 7, 922-930. [CrossRef] [PubMed]

17. Ying, T.; Feng, Y.; Wang, Y.; Chen, W.; Dimitrov, D.S. Monomeric IgG1 Fc molecules displaying unique Fc receptor interactions that are exploitable to treat inflammation-mediated diseases. MAbs 2014, 6, 1201-1210. [CrossRef] [PubMed]

18. Wang, L.; Ying, T. New Directions for Half-Life Extension of Protein Therapeutics: The Rise of Antibody Fc Domains and Fragments. Curr. Pharm. Biotechnol. 2016, 17, 1348-1352. [CrossRef] [PubMed]

19. Jespers, L.; Schon, O.; James, L.C.; Veprintsev, D.; Winter, G. Crystal structure of HEL4, a soluble, refoldable human V(H) single domain with a germ-line scaffold. J. Mol. Biol. 2004, 337, 893-903. [CrossRef] [PubMed]

20. Dudgeon, K.; Rouet, R.; Kokmeijer, I.; Schofield, P.; Stolp, J.; Langley, D.; Stock, D.; Christ, D. General strategy for the generation of human antibody variable domains with increased aggregation resistance. Proc. Natl. Acad. Sci. USA 2012, 109, 10879-10884. [CrossRef]

21. Bhatwa, A.; Wang, W.; Hassan, Y.I.; Abraham, N.; Li, X.-Z.; Zhou, T. Challenges Associated with the Formation of Recombinant Protein Inclusion Bodies in Escherichia coli and Strategies to Address Them for Industrial Applications. Front. Bioeng. Biotechnol. 2021, 9, 65. [CrossRef] [PubMed]

22. Leong, S.S.J.; Chen, W.N. Preparing recombinant single chain antibodies. Chem. Eng. Sci. 2008, 63, 1401-1414. [CrossRef]

23. Guglielmi, L.; Martineau, P. Expression of single-chain Fv fragments in E. coli cytoplasm. Methods Mol. Biol. 2009, 562, 215-224. [CrossRef] [PubMed]

24. Verma, R.; Boleti, E.; George, A.J. Antibody engineering: Comparison of bacterial, yeast, insect and mammalian expression systems. J. Immunol. Methods 1998, 216, 165-181. [CrossRef] 